\title{
Assessing the physical vulnerability of check dams through an empirical damage index
}

\author{
Andrea Dell'Agnese, ${ }^{1}$ Bruno Mazzorana, ${ }^{2}$ Francesco Comiti, ${ }^{1}$ Patricia Von Maravic,, \\ Vincenzo D'Agostino4
}

\author{
${ }^{1}$ Faculty of Science and Technology, Free University of Bozen-Bolzano, Italy; ${ }^{2}$ Department of \\ Hydraulic Engineering, Autonomous Province of Bolzano, Italy; ${ }^{3}$ Sustainable Europe Research \\ Institute, Vienna, Austria; ${ }^{4}$ Department of Land and Agroforest Environment, University of \\ Padova, Legnaro (PD), Italy
}

\begin{abstract}
A comprehensive analysis of flood risk in mountain streams has to include an assessment of the vulnerability of the protection systems, in addition to an assessment of the vulnerability of the constructed environment on alluvial fans and floodplains. Structures forming the protection systems are of a dual nature, i.e. they are designed to mitigate natural process-related hazards and, on the other hand, are prone to be damaged during their lifecycle by the same processes they should mitigate. Therefore, their effectiveness declines over time. Hence, the knowledge of how effectively control structures perform is essential for risk management. A procedure was developed to assess the physical vulnerability of check dams based on empirical evidence collected in South Tyrol, Northern Italy. A damage index defined on pre- and postevent comparisons of check dam conditions was evaluated for 362 structures in 18 mountain streams along with the relevant processes and the structural characteristics affecting it. Although the available dataset did not allow conclusive functional relationships between damage index and impact variables to be established, it was possible to assess the average expected residual functionality of check dams
\end{abstract}

Correspondence: Andrea Dell'Agnese, Faculty of Science and Technology, Free University of Bozen-Bolzano, piazza Università 5, 39100 Bolzano, Italy. E-mail: andrea.dellagnese@natec.unibz.it

Key words: vulnerability, flood risk, natural hazards, check dams.

Acknowledgements: we warmly thank Omar Formaggioni for his decisive support of this project, as well as Diego Mantovani, Bernhard Haninger and Stefan Hellweger for their help. Funding for the project was provided under the project AdaptAlp, an EU Alpine Space programme.

Received for publication: 5 November 2012 .

Accepted for publication: 23 March 2013.

(C) Copyright A. Dell'Agnese et al., 2013

Licensee PAGEPress, Italy

Journal of Agricultural Engineering 2013; XLIV:e2

doi:10.4081/jae.2013.e2

This article is distributed under the terms of the Creative Commons Attribution Noncommercial License (by-nc 3.0) which permits any noncommercial use, distribution, and reproduction in any medium, provided the original author(s) and source are credited. according to structure characteristics, and event type and intensity. These results may help plan appropriate check dam maintenance.

\section{Introduction}

The use of check dams to stabilise mountain streams has a long tradition in many Alpine regions. In South Tyrol, Northern Italy, the first check dams in masonry were built in the 16th century. As outlined by Mazzorana and Fuchs (2010b), in the second half of the 19th and during the early 20th centuries, protection against natural hazards was mainly provided by building permanent constructions in the upper part of the catchments, supplemented by afforestation of the valley slopes to reduce erosion and prevent initiation of debris flow. Due to the increasing demand for land for residential purposes and agricultural and industrial development, the consolidation approach was progressively extended to a larger number of streams. Despite the considerable investment in conventional mitigation strategies, which aimed at decreasing both the magnitude and frequency of events, losses could not be satisfactorily prevented (Mazzorana et al., 2008). It is economically and technically unfeasible to retain all the potentially transported sediment through retention and grade-control structures alike. Given this, since the late 1960 s, a large number of open, filtering check dams have been constructed (Zollinger, 1984). The functional efficiency of this type of structure was gradually refined (Üblagger, 1972) first by improving the mechanical sieving function and subsequently by modifying the design to obtain a cost-efficient dosing function (Armanini et al., 2000). Nonetheless, consolidation check dams built in staircase-like sequences, aimed at preventing bed incision and stabilising adjacent hill slopes, are widespread in Alpine streams and are still used today to mitigate flood and debris flow hazards. Indeed, approximately 30,000 check dams have been constructed in South Tyrol since 1900, and 16\% of them were judged not to satisfy required reliability and, consequently, technical efficiency requirements (Mazzorana et al., 2008). Tacnet et al. (2012) proposed decision support tools to analyse the efficiency of the protective measures taken considering both their structural state and functional capabilities. The hidden risk associated to check dam failure is especially important in cases of events larger than that in the design, whereas in cases of events of lower magnitude the related risk is more subtle (Von Maravic, 2010). Mazzorana et al. (2009) developed a formative scenario analysis technique to detect possible system changes for a protection system subjected to process impacts. However, the need for a comprehensive analysis of flood risk (here used broadly to include also debris flow processes) in mountain streams embracing the assessment 
of the vulnerability of the protection systems (i.e. check dams, levees, bank protection) in addition to the classical damage potential describing the built environment (Vorogushyn et al., 2009; Merz et al., 2010; Mazzorana et al., 2010b) is still to be addressed. Structures forming the protection systems are of a dual nature (Mazzorana et al., 2010a) because they are designed to mitigate natural process-related hazards but on the other hand they are prone to be damaged throughout their lifecycle by the same processes they should mitigate (Mazzorana, 2008; Vorogushyn et al., 2009), thus reducing their effectiveness over time. Furthermore, the sudden unexpected collapse of check dams can result in increased hazards downstream due to the formation of dam-break surges and the release of large volumes of sediments. In addition, the physical vulnerability of each single check dam contributes to the vulnerability of the entire channel control system, but the latter is not equal to the sum of the vulnerabilities of the single structures. In fact, because of the interrelationships between structural damage and event intensity, non-linear dynamics emerge making it difficult to predict the final state. Therefore, a reliable quantification of the physical vulnerability of each structure is essential for a correct understanding and prediction of the evolution of a given mountain stream during and following flood events.

Setting aside the social context, vulnerability can be defined as a functional relationship between process magnitude and/or intensity and the resulting impact on structural elements at risk. More specifically, with respect to the constructed environment, vulnerability is related to susceptibility of physical structures to damage, and can be defined as the expected degree of loss resulting from the impact of a certain event spectrum on the elements at risk. The assessment of vulnerability requires different parameters and factors to be evaluated, such as the type of element at risk and its resistance (Fuchs et al., 2007). Dealing with natural hazard processes, empirical parameters such as event magnitude and frequency must be assessed via the probability theory (Mazzorana et al., 2010b).

Unfortunately, still little is known about the consequences on check dams of the damage and impact related to a specific event (e.g. debris flow, debris flood/hyperconcentrated flow, intense bed load transport), and even less is known about how the initial physical conditions can influence the response to a certain stress. One way to shed some light on check dam vulnerability is through empirical investigation in the field by analysing a wide, representative sample of check dams, including different structural conditions, types of events and related intensities. These data can be used to perform a statistical analysis to determine the factors affecting the physical vulnerability of check dams, and to explore possible quantitative relationships between loading parameters and the defined damage indices for different types of structures. This will help us understand how information acquired in the field and the results of hazard analysis can be used to maintain the preventive capability of the check dams, and consequently lower the risk to the protective system and to the constructed environment. This paper presents the research carried out in South Tyrol, Northern Italy.

\section{Materials and methods}

The study area for the empirical analysis of physical vulnerability of check dams is represented by 18 mountain streams belonging to the Adige/Etsch river basin, in South Tyrol, Northern Italy (Figure 1). These 18 streams were selected among other possible candidates because of the availability of both written and photographic documentation on structural conditions of the constructions before recent (from 2007 to 2010) relevant events. The study basins include meta- morphic, porphiric, granitic and calcareous rock substrate, with channels with a bed slope ranging from 0.03 to $0.50 \mathrm{~m} / \mathrm{m}$.

The dataset consists of 362 check dams and a total of 22 flood events (including debris flows and debris flood events). Most of the flood events analysed occurred in 2009, a year characterised by a large number of events, with the main storms on $16^{\text {th }}$ and $17^{\text {th }} \mathrm{July}, 30^{\text {th }} \mathrm{July}$ and $4^{\text {th }}$ September. In summer 2010, two operators carried out the field evaluations of post-event conditions of check dams, along with event characterisation.

The vast majority of check dams comprised in the dataset are concrete consolidation structures (59.4\% of the case studies) or steel-reinforced concrete check dams (20.2\%). A smaller but important part of the dataset consists also of boulder check dams, reinforced $(8.8 \%)$ or not reinforced (4.1\%) with concrete/grout and retention concrete check dams (3.9\%) Other materials were also considered, but their presence in the dataset is almost negligible in comparison. Most of the check dams analysed were built in the last 20 years ( $22 \%$ in the last decade, $44.3 \%$ between 1990 and 2000), with the remaining check dams in our dataset dating from the late 1950s onwards (Tables 1 and 2).

The paper will first discuss the variables describing the loading conditions for the analysed structures in South Tyrol, followed by the formal definition of the damage index, based on pre-and post-event structure conditions. The set up and necessary assumptions for data analysis will also be outlined.

\section{Definitions of the variables used for event intensity and check dam design}

In order to describe and quantify event intensity, and to complement the immediate post-event surveys including photographic documentation carried out by the Ripartizione Opere Idrauliche (Dept. of Hydraulic Engineering) of the Province of Bolzano, two different spatial scales were analysed by the field operators in summer 2010 , i.e. a local scale referring to the channel portion closely (tens of meters) surrounding every single structure, and a reach scale referring to a longer (hundreds of meters) channel segment. At the local scale, the relevant variables surveyed were the maximum flow depth $(H$, in $\mathrm{m})$ and width ( $W$, in $\mathrm{m}$ ) during the event, the maximum diameter of transported clasts found near the structure (Dmax, in $\mathrm{m}$ ), and the local bed slope (Sloc, in $\mathrm{m} / \mathrm{m}$ ). At the reach scale, the channel slope (SREACH in $\mathrm{m} / \mathrm{m}$ ) was measured over a distance of approximately $500 \mathrm{~m}$.

From the surveyed variables, the following hydraulic variables were calculated: maximum flow discharge (at the reach scale), unit water discharge and the unit stream power (both at the local scale).

The maximum flow discharge was calculated as: $Q=H \cdot W \cdot V$, where $V$ is the mean flow velocity (in $\mathrm{m} / \mathrm{s}$ ). The velocity was calculated in two different ways, depending on the event type. For debris flows (D), velocity was calculated using Rickenmann's (1996) equation (Eq. 1) to match with observed flow depth and width:

$$
V=2.1 Q^{0.33} S_{R E A C H}^{0.33}
$$

whereas for bed load (B) and debris floods (H), velocity was calculated by assuming critical flow conditions (i.e. Froude number of the flow $F r=1$ ), following indications for floods in steep channels by Grant (1997) and Comiti et al. (2009a) (Eq. 2):

$$
V=\sqrt{g H}
$$

where

$g$ is the gravitational acceleration. The unit discharge was then calculated simply as $q=Q / W$. 
The unit stream power $\omega$ was defined as:

$\omega=\Omega / W$

where $\Omega$ is the reach-scale stream power, defined through the following equation:

$$
\Omega=\frac{g \rho Q S_{L O C}}{W}
$$

where

$\rho$ is $2000 \mathrm{~kg} / \mathrm{m}^{3}$ for $\mathrm{D}, 1500 \mathrm{~kg} / \mathrm{m}^{3}$ for $\mathrm{H}$ and $1000 \mathrm{~kg} / \mathrm{m}^{3}$ for $\mathrm{B}$.

Besides the above variables related to event intensity, the design discharge $Q D$ for each check dam was defined based on pre-event geometry in order to rate events in comparison with design values. $Q D$ was calculated as the product of the spillway area and critical mean flow velocity calculated over the spillway, similarly to Eq. 2.

\section{Assumptions for data analysis}

As previously stated, the entire dataset of check dams ( $n=362)$ is composed of two subsets associated to two different field operators and to different levels of hydraulic analysis. Both subsets will be analysed jointly with respect to the variables affecting check dam vulnerability and to those describing event loading (e.g. bed slope, age and type of structure) because differences between the two operators in the assessment of the damage index and of the residual functionality of each structure are considered to be negligible. However, only Subset $1(n=174)$ estimates event
Table 1. Types of check dams as classified by the Province of Bolzano, Northern Italy.

\begin{tabular}{lc} 
Code & Material type \\
1 & Retention concrete \\
2 & Dosing concrete \\
\hline 3 & Consolidation concrete \\
4 & Mixed masonry \\
\hline 5 & Uncemented boulder \\
6 & Cemented boulder \\
\hline 7 & Steel-reinforced concrete \\
\hline & Masonry with wood \\
\hline
\end{tabular}

Table 2. Check dam age classes.

\begin{tabular}{lc} 
Code & Age (years) \\
1 & $<10$ \\
2 & $10-20$ \\
\hline 3 & $20-30$ \\
4 & $30-40$ \\
\hline 5 & $40-50$ \\
6 & $50-60$ \\
\hline
\end{tabular}

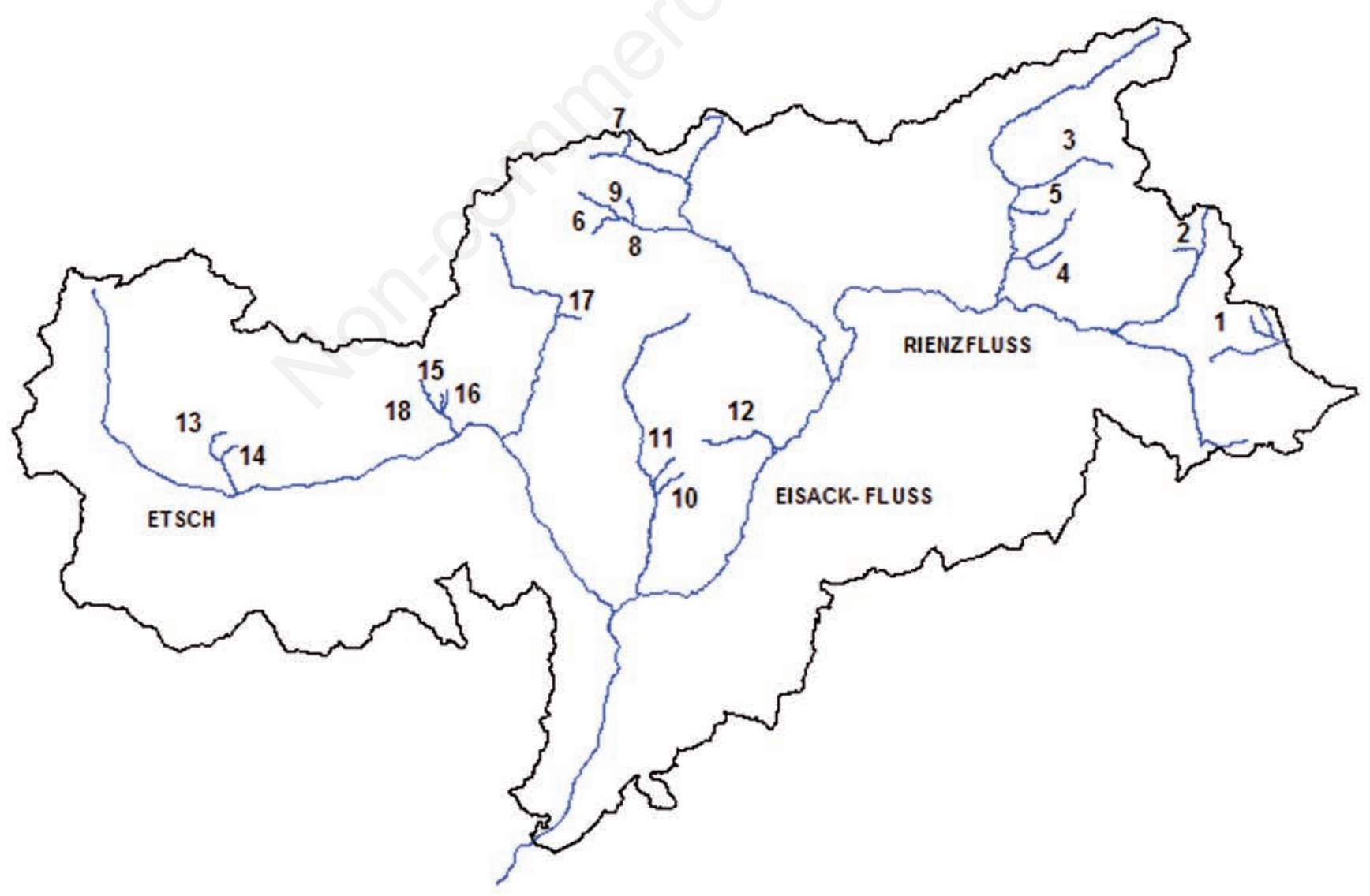

Figure 1. Location of the 18 case studies in South Tyrol, Northern Italy. 
flow characteristics based on Eqs. 1-4, as well as the design discharge adopted for each check dam. Hence, only data from Subset 1 will be used to look for statistical relationships between damage index and event flow characteristics. In fact, the estimation of a reach-scale flow discharge for Subset $2(n=188)$, carried out by a different operator (Von Maravic, 2010), is more difficult and subject to a larger degree of uncertainty. Nonetheless, data relative to the maximum sediment size transported by the event collected in Subset 2 will be used.

Within Subset 1, not all the variables (either geometrical or hydraulic) were available for some check dams, and these cases were, therefore, dropped. Also, to achieve statistically significant results, the few (1-2 each) cases of structure types 1, 2 and 8 (retention, dosing and masonry with wood check dams) were removed, therefore focussing on consolidation check dams of types $3,4,5,6$ and 7. Age class ranged from 1 to 6 (but Class 5 is missing), and all types of events were included (bed load, debris flood and debris flow). The final sample size for Subset 1 is made up of 156 cases out of the initial 174 check dams. In order to analyse different streams together, for each check dam, the peak discharge $Q$ estimated from field surveys was normalised by the estimated design discharge $Q D$. Similarly, flow depth $(H)$ and width $(W)$ were made dimensionless by dividing them by overflow depth $(h)$ and crest width $(w)$, respectively, whereas the maximum diameter Dmax was divided by the check dam thickness $(d)$.

In order to establish a loading variable associated to the event, only a reach-scale flow discharge estimated on the most stable sections was considered reliable. The highest marks observed in the field in these sections were taken as an indicator of flow depth. Velocity estimations use this average event flow depth. Field estimation of flow width is probably affected by a much smaller error than depth and can, therefore, be used to calculate local unit discharge. For these reasons, flow depth measured locally will be not used to evaluate event loading. Clearly, the use of a single, reach-scale discharge for all the check dams within a reach assumes that discharge remained constant along the channel, which may be not true, especially for long reaches and with debris flow phenomena. Local scale properties that are probably relevant for check dam stability (i.e. unit stream power derived from unit discharge) can be derived from the reach-scale discharge using local flow width and local channel slope.

The statistical analysis was carried out using Statistica 7.0 software (2004; StatSoft Inc., Cary, NC, USA). Indeed, it must be stressed that even though the results presented here were derived from a relatively large sample $(n=362)$, they are representative of only a small portion of the entire population of check dams in South Tyrol, which feature varying combinations of structure and basin characteristics.

\section{Damage index based on pre- and post-event structure conditions}

As stated above, vulnerability can be defined as the expected degree of loss resulting from the impact of a certain event on the elements at risk. Hence, considering check dams as these elements, it is necessary to compare their pre- and post-event conditions and to quantify the damage events in terms of structural deterioration relative to the preevent conditions. In order to do this, a damage index function is introduced as a general procedure.

The damage index function $(D I i)$ for the ith check dam is defined as follows:

$D I_{i}=D I_{i}\left(\operatorname{Re}_{i}\left(I_{E}\right)\right)$

where

$\operatorname{Re}_{i}\left(I_{E}\right)$ is the resistance of the check dam in case of an event $\mathrm{E}$ of intensity $I_{E}$. Due to the difficulties in determining $\operatorname{Re}_{i}\left(I_{E}\right)$ directly, it is practical to re-state Eq. 5 in the following form:
$D I_{i}=D I_{i}\left(\Delta C_{i},\left(\operatorname{Re}_{i}\right)_{j}, L\left(I_{E}\right)_{m}\right)$

where

$\Delta C_{i}=C_{i}$ post- $C_{i}$ pre is a measure of the structural changes in check dam conditions $C$ resulting from the event $E,\left(R e_{i}\right)_{j}$ where $\mathrm{j}=1, \ldots, \mathrm{J}$ are the $\mathrm{J}$ considered resistance descriptors for each check dam, and $L\left(I_{E}\right)_{m}$, $\mathrm{m}=1, \ldots, \mathrm{M}$ are the $\mathrm{M}$ parameters for the description of the loading conditions of the event $E$.

A number $K$ of functional parts of check dams are defined (Figure 2). Each of these functional parts is assessed (based on photographs and field surveys) for both pre- and post-event conditions through an integer ranking value $R$, ranging from 1 (no damage to the functional part analysed) to 5 (complete damage to functional part). By applying the ranking $R$ to the assessment of the $K$ functional parts in pre- and postevent conditions, $\left(R_{k}\right)^{p r e}$ and $\left(R_{k}\right)^{\text {post }}$ respectively, a vector quantifying the relative change in structural performance can be obtained as follows:

$\vec{\Delta}=\left(\Delta_{k}, \ldots ., \Delta_{K}\right)=\left(\left(R_{1}\right)^{\text {pre }}-\left(R_{1}\right)^{\text {post }}, \ldots \ldots,\left(R_{K}\right)^{\text {pre }}-\left(R_{K}\right)^{\text {post }}\right)$

A vector of weights $\vec{w}=\left(w_{1}, \ldots, w_{K}\right)$ is then defined expressing the relative importance of each functional part (contribution to the overall functionality of the check dam). Finally, the damage index $\left(\mathrm{DI}_{\mathrm{i}}\right)$ for each check dam can be calculated as weighted average of the single elements of the structural performance change vector (compare Eq. 7) as follows:

$\vec{w}=\left(w_{1}, \ldots, w_{K}\right)$

with $\sum_{k=1}^{K} w_{k}=1$.

In our specific case, we assessed, for a large number of check dams, the damage index $D I$ relative to recent flood events whose intensity indicators, $L\left(I_{E}\right)_{m}$ (i.e. type of event, discharge, local energy slope, unit stream power, sediment size, flow width and depth) have been estimated by field surveys and supported by the event documentation archives of the Autonomous Province of Bolzano. The selected resistance descriptors $\left(R e_{i}\right)_{j}$ are the main geometrical data of the check dams (i.e. height and width, dimensions of the wings and of the foundation, etc.) which have been assessed both for pre- and post-event conditions also accounting for check dam type (Table 1) and age (Table 2). Following the procedural steps outlined above, the damage conditions (Eq. 8) were assessed dividing the structure into $K=6$ different functional parts (Figure 2), each having the same weight $w k$.

Finally, the residual functionality $R F$ of each check dam at the time of survey was categorised according to the classes (codes 1-4) listed in Table 3. The residual functionality represents an integrated evaluation of the degree of performance (in our case, mostly bed level consolidation) the structure still exerts. $R F$ differs from the evaluation of the damage extent for the different parts (ranking $R$ described above) because it entails a holistic assessment approach to each check dam condition, basically aimed at defining whether the structure is still of use or not, and if it needs structural restoration. However, $R F$ is clearly linked to $D I$, and the determination of the threshold of damage levels leading to Heavily compromised functionality (Class 3 , Table 3 ) becomes of great interest in terms of the maintenance measures to be taken. 


\section{Results}

\section{Damage index and residual functionality}

The link between damage index $D I$ and residual functionality $R F$ is presented in Figure 3. The existence of a strongly significant $(\mathrm{P}<0.001$, based on one-way ANOVA) relationship is quite obvious, i.e. the greater the damage, the smaller the remaining functionality. But the graph is relevant because it highlights the $D I$ values at which substantial changes in functionality occur. The step from $R F=2$ to $R F=3$ reflects a difference reckoned substantial in terms of functionality, even though the increase in average $D I$ is apparently not major (approx. 0.15-0.28), in contrast to the sharp increase associated to the passage from $R F=3$ to $R F=4$ (no residual functionality, i.e. functionality totally lost). Therefore, $D I$ higher than approximately 0.2 should be viewed as indicating alterations likely to bring about serious consequences in terms of functionality during future events. Furthermore, the loss of residual functionality was found to have the highest correlation with the level of damage on the central crest of check dams $(\mathrm{R}=0.85)$ However, this derives from the definition of functionality for consolidation check dams, i.e. fixing the bed level at their crest. Indeed, damage to wings also shows significant correlation with $R F(\mathrm{R}=0.66)$ and has the potential to bring about important structural failures.

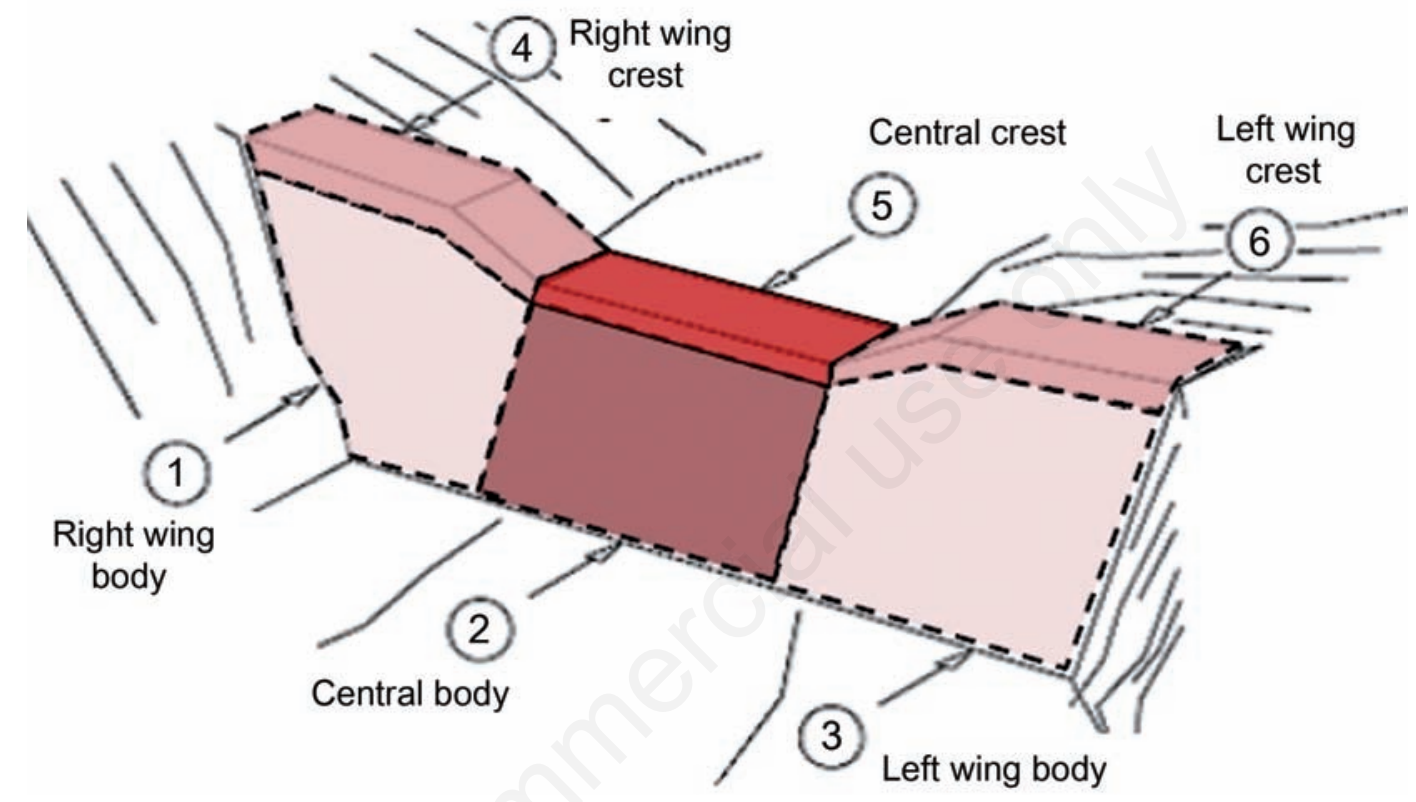

Figure 2. Every check dam was subdivided into six parts to assess damage.

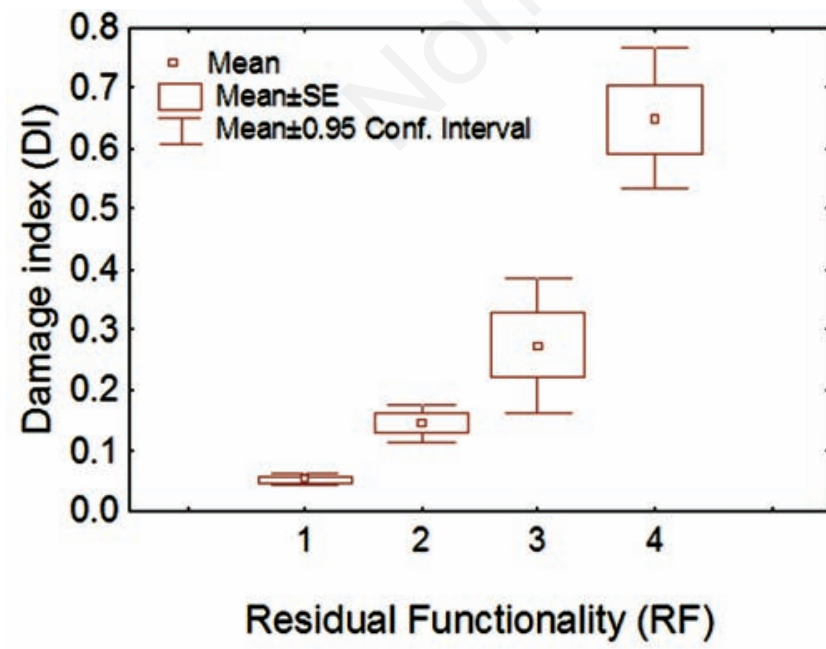

Figure 3. Relationship between residual functionality and damage index. RF 1, unaltered functionality; 2, slightly compromised; 3, heavily compromised; 4 , no residual functionality.
Table 3. Residual functionality classes.

\begin{tabular}{cc} 
B & Residual functionality \\
1 & Unaltered functionality \\
2 & Slightly compromised functionality \\
\hline 3 & Heavily compromised functionality \\
4 & No residual functionality \\
\hline
\end{tabular}

Table 4. Results of main effects of analysis of variance for damage index applied to the entire dataset.

\begin{tabular}{lccccc} 
& $\begin{array}{c}\text { Sum of } \\
\text { squares }\end{array}$ & $\begin{array}{c}\text { Degree of } \\
\text { freedom }\end{array}$ & Mean & F & P \\
Intercept & 4.28 & 1 & 4.28 & 166.98 & $<0.001$ \\
Structure type & 2.22 & 7 & 0.32 & 12.37 & $<0.001$ \\
\hline Structure age & 1.09 & 5 & 0.22 & 8.53 & $<0.001$ \\
Event type & 0.16 & 2 & 0.09 & 3.05 & $<0.05$ \\
\hline Pre-event damage & 0.03 & 1 & 0.03 & 0.98 & $>0.10$ \\
Error & 8.86 & 346 & 0.02 & - & - \\
\hline
\end{tabular}

Significant $(\mathrm{P}<0.05)$ values are in italics. 


\section{Physical vulnerability: determination of significant factors}

Several preliminary one-way ANOVAs were carried out by analysing the entire dataset to find significant effects on the damage index $(D I)$ due to the different categorical variables such as structure age, type, and function, event type and presence/absence of pre-event damage. These single-variable ANOVAs identified all of these categorical variables as having significant effects $(\mathrm{P}<0.05)$ on $D I$, except for structure function: i) older ( $>20$ years) structures have higher $D I$ than newer ones; ii) concrete check dams have lower DI than masonry ones; iii) previously damaged structures have higher $D I$. With reference to event type, the one-way ANOVA indicates that DI associated to debris flood events is on average higher than for debris flow and bed load events, which do not differ between themselves.

However, because the dataset is made up of only a limited number of the possible combinations among these factors, there is a need to use main-effects ANOVAs (i.e. an analysis which includes more categorical variables at a time) to assess the contribution of each one to the overall variance of $D I$. The results obtained from such an analysis, including all the variables, except for structure function, are reported in Table 4.

All but pre-event damage is found to be significant, with event type showing a weaker effect than the other variables. With reference to structure type, the ANOVA indicates that, apart from the single and thus non-representative case of masonry and wood structure (type 8) which features the highest average $D I$, uncemented boulder and mixed masonry check dams (types 5 and 4, respectively) show higher DI. Also, there is a significant difference between uncemented (type 5) and cemented (type 6) boulder structures, with the latter demonstrating lower damage levels, almost comparable to reinforced concrete check dams. As regards age, there is a significant steady increase in $D I$ as check dams become older up to class 4 (40 years), then an abrupt increase in $D I$ can be seen for class 6 . However, only a few cases belong to this class, thus the associated error is quite large. Finally, debris flow events seem to bring about more major damage, in contrast to values obtained from the simpler oneway ANOVA mentioned above. However, the difference between debris floods and bed load events is not significant $(\mathrm{P}>0.05)$.

A correlation analysis has also been carried out to detect possible effects of quantitative variables such as the size of different parts of check dams, the channel slope (local and reach scale), the maximum size of transported clasts during the event, and also estimated flow depth and flow width (here flow depth is used with no reference to the actual event loading but just as an overall indicator). Results are reported in Table 5. There are some check dams dimensions that seem to be positively correlated to damage, i.e. structure height $(h)$, thickness $(d)$, and width $(L)$. Channel slope does not seem to be related to damage.
The event-related variable featuring the highest correlation is Dmax, but also flow depth and width display significant correlations. These three variables are also significantly positively cross-correlated among themselves; this is as expected since they are usually positively correlated with flow discharge (Table 6). Channel slope (both local and reach-averaged) results significantly $(\mathrm{P}<0.05)$ correlated $(\mathrm{R}=-0.133$ and -0.198 , respectively) only with flow width, i.e. the steeper the channel the narrower the flow.

The significant correlation of these variables with the damage index is confirmed also by an analysis of covariance including them each one at a time in a model with the following variables: structure type, age and event type. In the same models, channel slopes are not significant. When both flow depth and maximum diameter are included in the model together, only the former appears to be significant $(\mathrm{P}<0.05)$. Certainly, flow depth is, in most cases, positively correlated to flow discharge, but as explained above, only for Subset 1 are we confident enough to derive the latter variable (at reach scale) from flow depth estimation. The analysis involving flow discharge and unit stream power for Subset 1 is presented below.

\section{Physical vulnerability: relationship with event magnitude}

In order to include event intensity into the analysis of variance like those described for the complete dataset, a categorical variable describing event intensity was then assigned to each check dam based on the ratio $Q / Q D$ : low intensity (1) for $Q / Q D<0.5$, medium intensity (2) for $0.5<Q / Q D<1.5$, high intensity (3) for $Q / Q D>1.5$. The boundaries between the three classes derive from the distribution of the ratio in the sample and were set to ensure a reasonable number of cases in all the three classes. A one-way ANOVA shows that the damage index DI differs statistically depending on event intensity (Figure 4), but only between Class 3 (high) and the other lower classes. The difference between low and medium events is not significant, even though Class 2 features $D I$ that is on average higher than Class 1 .

However, it is hypothesised that other factors are also relevant for check dam vulnerability, i.e. type and age of structure, and event type. Therefore, a mean effects ANOVA test was performed (Table 7). The statistical model is significant $(\mathrm{P}<0.001)$ and the variance explained by the model is quite high (adjusted $R 2=0.74$ ). The ANOVA test indicates that the most relevant factors affecting the physical vulnerability of check dams are their type and age. In particular, mixed masonry and boulder check dams (types 4 and 5 , respectively) are the most vulnerable. Interestingly, concrete boulder check dams do not appear to differ

Table 5. Pearson's correlation coefficient $R$ between damage index and different variables.

\begin{tabular}{|c|c|c|c|c|c|c|c|c|c|c|c|c|c|c|c|c|}
\hline Variable & h & b & hr & br & wr & hl & bl & wl & f & d & L & Sloc & SREACH & $D \max$ & $\mathrm{H}$ & W \\
\hline $\mathrm{R}$ & 0.19 & 0.1 & 0.01 & 0 & 0.26 & 0.02 & 0.01 & 0.08 & 0.02 & 0.25 & 0.18 & 0.1 & 0.11 & 0.48 & 0.37 & 0.21 \\
\hline
\end{tabular}

h, height of the structure measured at its mid section; b, spillway width; hr, right spillway depth; br, right spillway width; wr, right wing length; hl, left spillway depth; bl, left spillway width; wl, left wing length; f, depth of the foundation; d, check dam thickness (measured at the spillway level): L, total width of the check dam (sum of wings and spillway); Sloc, local bed slope; SREACH, reach scale; Dmax, max transported clast; $\mathrm{H}$, flow depth; $W$, flow width. $R$ values at significant levels $(\mathrm{P}<0.05)$ are in italics.

Table 6. Pearson's correlation coefficient $R$ among event related variables.

\begin{tabular}{lcccc} 
& H & W & Dmax \\
H & 1 & 0.533 & 0.395 & 0.308 \\
W & 0.533 & 1 & 1 \\
\hline $\max$ & 0.395 & 0.308 & 1 \\
\hline
\end{tabular}

H, flow depth; W, flow width; Dmax, max transported clast. $\mathrm{R}$ values at significant $(\mathrm{P}<0.05)$ levels are in italics. 
significantly from concrete and steel reinforced check dams. As far as age of the structure is concerned, the increase in vulnerability over time is evident from Class 4 to 5 and 6, i.e. for check dams older than 30 years. The higher damage index for Class 1 (the newer structures) than for Class 2 probably depends on the dataset used, but there is no clear reason for this. Event type is seen to be significant, with debris flows featuring worse damage. But the large difference between bed load and debris floods is thought to stem either from the uncertainties inherent in labelling the event in some cases, or from the use of weaker check dams in channels not prone to debris flow processes. Interestingly, event intensity is not found to be statistically significant by this complete ANOVA analysis (including all the factors), in contrast to the one-way ANOVA described above, suggesting that overall check dam conditions are more important than event intensity. A qualitative assessment of the database also suggests that a quite relevant factor (actually possibly determining whether a structure will collapse or not) is represented by erodibility of the banks as this strongly affects wing stability. Wings protected by cemented pillars or well inserted into bedrock may prevent lateral erosion and thus provide more stability to the structure.

In order to help guide river managers, we propose a matrix (Table 8) to summarise the expected residual functionality $(R F)$ of check dams of different types and featuring varying initial $R F$ values following events of different relative magnitudes. This goes from 1 (unaltered functionality) to 4 (no residual functionality, i.e. resulting non-func-

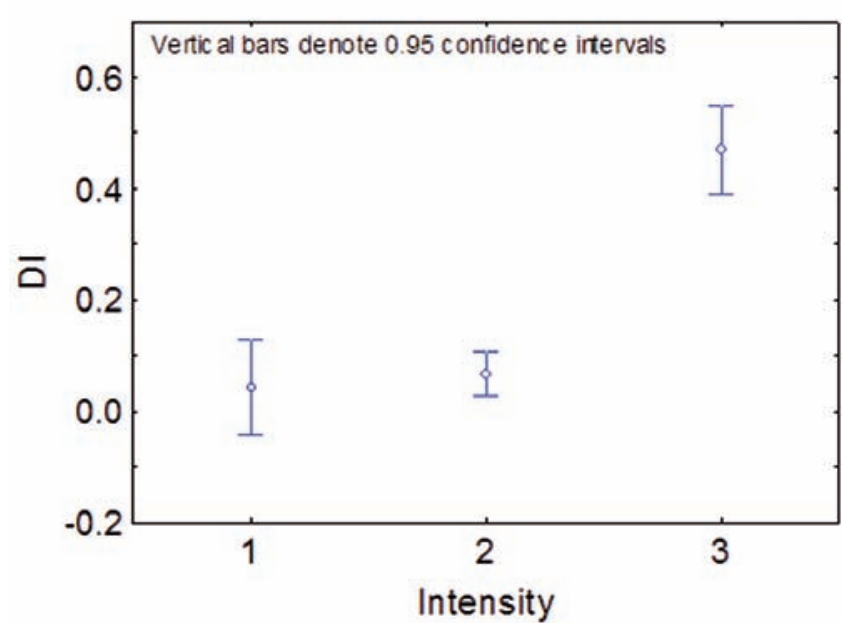

Figure 4. Results of one-way ANOVA on damage index (DI) with event intensity based on the $Q / Q D$ ratio. 1 , low intensity event, $\mathrm{Q} / \mathrm{QD}<0.5 ; 2$, medium intensity, $0.5<\mathrm{Q} / \mathrm{QD}<1.5 ; 3$, high intensity $Q / Q D>1.5$.

Table 7. Results of mean effects analysis of variance on damage index applied to Dataset 2.

\begin{tabular}{|c|c|c|c|c|c|}
\hline & Sum of squares & Degree of freedom & Mean squares & F & P \\
\hline Intercept & 4.124 & 1 & 4.124 & 235.27 & $<0.001$ \\
\hline Structure type & 0.820 & 4 & 0.205 & 11.699 & $<0.001$ \\
\hline Structure age & 1.287 & 4 & 0.321 & 18.360 & $<0.001$ \\
\hline Event type & 0.170 & 2 & 0.085 & 4.852 & $<0.01$ \\
\hline Event intensity damage & 0.066 & 2 & 0.033 & 1.883 & $>0.10$ \\
\hline Error & 2.506 & 143 & 0.017 & - & - \\
\hline
\end{tabular}

Significant $(\mathrm{P}<0.05)$ values are in italics.

Table 8. Vulnerability matrix for consolidation check dams. This matrix describes the average expected values for residual functionality (RF) of check dams as a function of structure characteristics (rows, with type and initial RF values) and event intensity and type (columns). Event intensity is expressed as type of event, discharge, local energy slope, unit stream power, sediment size, flow width and depth. In cases of very stable banks/wings, RF values are expected to decrease by 1 . The matrix does not consider cases of excessive local scouring compared to check dam foundations.

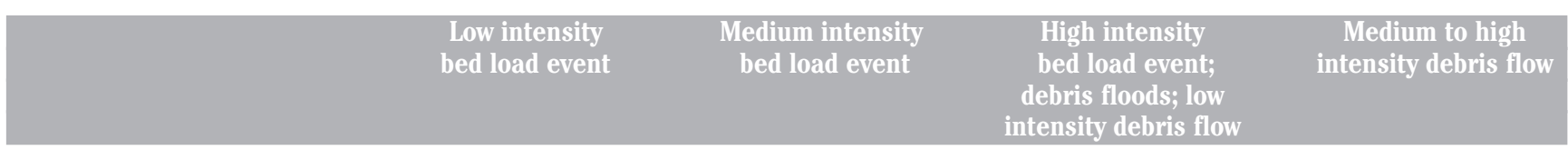

$\begin{array}{ll}\text { Uncemented boulders and/or wood } & \\ 1 & 2 \\ 2 & 3 \\ 3 & 4 \\ \text { Cemented boulders and masonry } & \end{array}$

\begin{tabular}{lllll} 
Cemented boulders and masonry & & & 3 & 4 \\
1 & 1 & 2 & 4 & 4 \\
2 & 2 & 3 & 4 & 4 \\
3 & 3 & 4 & 2 & 2 \\
Concrete and steel-reinforced concrete & & & 3 & 3 \\
1 & 1 & 3 & 3 & 4 \\
2 & 2 & 3 & 3 & \\
3 & 3 & 3 & & \\
\hline
\end{tabular}


tional) (Table 3). The matrix has only been designed for consolidation check dams (grade control works) and not for filtering or retention check dams. It was derived from the statistical results reported above. Table 8 is also the result of several years of field surveys in rivers that have undergone different processes and that have different protection systems. This experience allowed the authors to assess uncertain parameters for which there were no clear indications in the field observations. Indications from a case study in the Province of Trento, Northeastern Italy (Lenzi et al., 2003; Comiti et al., 2009b), were also used. The matrix does not consider the case of excessive local scouring compared to the depth of check dam foundations because the available dataset did not allow us to analyse this process. However, relevance of local scouring in undermining check dams should always be taken into account (Comiti et al., 2010).

The matrix is meant to represent only a first, preliminary tool to estimate the physical vulnerability of check dams. It is intended as a starting point to plan the preventive maintenance of check dams, using both information derived from hazard management and from field surveys of the actual conditions of check dams in order to identify where appropriate maintenance is required. In this way, hazard and risk patterns can be modified. More investigations in streams featuring different structure types and/or age following events of different intensities must be carried out to refine and validate the proposed ranking.

\section{Conclusions}

The collected dataset did not allow reliable relationships between event characteristics and expected damage to check dams to be established. This is because many variables other than event intensity have some influence on the physical vulnerability of these structures, i.e. type, age, geometry, pre-event conditions, event type. This results in an extremely high number of possible combinations to be assessed in order to determine continuous relationships (i.e. regression equations) for each combination. Since it is not possible to test all these factors in the laboratory, we need to use what prototypes we can. However, this has several limitations because it requires recent events to be surveyed or events from the past to be very well documented. In addition, bank erodibility is an important factor as this strongly affects wing stability. Unfortunately, it is quite difficult to use this as a parameter, and this limits our ability to predict the damage index even more.

Despite these problems, the present study allowed us to investigate the link between the extent of damage (the damage index) to check dams and their residual functionality. The functionality of check dams becomes critically impaired for $D I$ over 0.2 , and this level of damage can derive from events with intensity (discharge) larger than approximately half the design discharge of the structures (Class 2), regardless of type and age of structure. Therefore, also events with a return period shorter than that used for the hydraulic and static design of check dams are likely to cause substantial damage to these structures. This outcome should be considered when accounting for and determining maintenance costs of check dams within their desired lifespan. Structures older than 30-40 years are very likely to present substantial damage and thus poor functionality. Another clear conclusion from the present study is that boulder structures should not be built in channels where debris floods can occur, i.e. in our cases, with slopes over $0.10-0.15$, unless they are small in height and well anchored to banks with almost negligible erodibility.

\section{References}

Armanini A., Larcher M. 2000. Rational criterion for designing opening of slit-check dam. J. Hydraul. Eng. 127:94-104.

Comiti F., Cadol D., Wohl E. 2009a. Flow regimes, bed morphology, and flow resistance in self-formed step-pool channels. Water Resour. Res. 45:W04424.

Comiti F., Lenzi M.A., Mao L. 2010. Local scouring at check dams in mountain rivers. In: M. Conesa-Garcia, M.A. Lenzi (eds.) Check dams, morphological adjustments and erosion control in torrential streams. Nova Publ., Hauppauge, NY, USA, pp 263-82.

Comiti F., Mao L., Lenzi M.A., Siligardi M. 2009b. Artificial steps to stabilize mountain rivers: A post-project ecological assessment. River Res. Appl. 25:639-59.

Fuchs S., Heiss K., Hübl J. 2007. Towards an empirical vulnerability function for use in debris flow risk assessment. Nat. Hazards Earth Syst. Sci. 7:495-506.

Grant G.E. 1997. Critical flow constrains flow hydraulics in mobile-bed streams: a new hypothesis. Water Resour. Res. 33:349-58.

Lenzi M.A., Comiti F. 2003. Local scouring and morphological adjustments in steep channels with check-dam sequences. Geomorphology. 55:97-109.

Mazzorana B. 2008. Das EF30Forward Konzept: ein Hinweisinstrument zur Ermittlung der Zuverlässigkeit und Funktionseffizienz von Wasserschutzbauten. Interpraevent 2008. Internationale Forschungsgesellschaft Interpraevent, Klagenfurt, Austria, 1:415-24.

Mazzorana B., Fuchs S. 2010a. A conceptual planning tool for hazard and risk management. pp 828-837 in Internationales Symposium Interpraevent, Taipei, Taiwan.

Mazzorana B., Fuchs S. 2010b. Fuzzy formative scenario analysis for woody material transport related risks in mountain torrents. Environ. Model. Software. 25:1208-24.

Mazzorana B., Hübl J., Fuchs S. 2009. Improving risk assessment by defining consistent and reliable system scenarios. Nat. Hazards Earth Syst. Sci. 9:145-59.

Mazzorana, B., Scherer, C., Marangoni, N. 2008. Additional torrent control strategies on debris flow alluvial fans with extremely high vulnerable settlements. pp 1492-1499 in Proc. iEMSs 2008 - Int. Environ. Moldelling Software Soc., Barcelona, Spain.

Merz B., Kreibich H., Schwarze R., Thieken A. 2010. Assessment of economic flood damage. Nat. Hazards Earth Syst. Sci. 10:1697-724.

Rickenmann D. 1996. Fliessgeschwindigkeit in Wildbächen und Gebirgflüssen. Wasser, Energie, Luft 88:298-304.

Tacnet J.-M., Curt C., Benjamin R., Richard D. 2012. Efficiency assessment for torrent protection works - An approach based on safety and reliability analysis. Int. Symp. Interpraevent - Grenoble (23-26 April). Internationale Forschungsgesellschaft Interpraevent, Klagenfurt, Austria, 2:821-31.

Üblagger G. 1972. Retendieren, Dosieren und Sortieren. (Retaining, dosing and sizing). Mitteilungen der forstl. Bundesversuchsanstalt, Wien, Austria, 102:335-72.

Von Maravic P. 2010. Evaluation of the physical vulnerability of checkdams exposed to the impacts of torrential processes through experimental analysis. Degree Diss., University of Padova, Italy.

Vorogushyn S., Merz B., Apel H. 2009. Development of dike fragility curves for piping and micro-instability breach mechanisms. Nat. Hazards Earth Syst. Sci. 9:1383-401.

Zollinger F. 1984. Die verschiedenen Funktionen von Geschieberück-haltebauwerken. Internationales Symposium Interpraevent, Tagungspublikation, Villach, Austria, 1:147-60. 